\title{
De que criança(s) estão falando?: Análise dos memes veiculados no Brasil no período da pandemia do coronavírus
}

\author{
Juliana Prates Santana ${ }^{1}$; Larissa dos Santos Fraga ${ }^{2}$; Leila Mignac Ferrari ${ }^{3}$; Camila Pinho de Mello ${ }^{4}$
}

\section{Introdução}

O presente texto objetiva refletir sobre as imagens de infâncias e crianças que emergem no contexto brasileiro no momento da pandemia mundial causada pelo coronavírus, a partir da análise de memes que circularam nas redes sociais, após a adoção da estratégia de distanciamento social para contenção da disseminação da doença.

O fechamento das escolas, adoção do trabalho remoto e permanência no contexto doméstico apenas das pessoas que compõem o núcleo familiar restrito impôs uma nova forma de sociabilidade para parte da sociedade, sendo o contexto das famílias com crianças frequentemente retratado nos memes. Trata-se da oportunidade de discutir sobre as imagens sociais que caracterizam as crianças e as infâncias e que não foram criadas a partir da pandemia, mas que nesse momento de crise foram explicitadas através do recurso do humor e da sátira, denunciando as desigualdades de infâncias e a forma como esse grupo geracional tem sido concebido e retratado.

A compreensão de que a infância refere-se a uma categoria social do tipo geracional, socialmente construída e não uma categoria biológica, universal remonta os estudos de Philippe Àries e tem sido amplamente discutida na área dos Estudos Sociais da Infância (James, Jenks e Prout, 1998; Sarmento, 2007; Qvortrup, 2009; Corsaro, 2018). Se em sua pesquisa Àries utilizou como fonte de dados, as pinturas da época, pode-se dizer que os memes que circulam nas redes sociais, podem representar um pouco o discurso social sobre infâncias na atualidade. Pode-se afirmar, pelo seu caráter viral, que a memética consegue captar características importantes sobre grupos sociais, sendo materiais culturais que demonstram opiniões através do humor.

Para Shifman, o meme é um item digital propagado enquanto uma mídia, em formatos diversos, como texto e imagens, e que só podem ser analisados à partir de seu contexto, entendendo que essa mídia é parte de um grupo maior com características próximas (Chagas, 2020). Ademais, como pontuado por Chagas (2020), Shifman também sinaliza que os memes são "postos em circulação", ou seja, evidencia a agência humana na memética.

\section{Justificativa}

Um dos motivadores deste trabalho foi a forma caricata e até violenta como as crianças foram retratadas nas publicações quando as escolas fecharam. Eclodiu no discurso social uma imagem infantil que parecia estar latente, mas que não era dita de forma explícita antes da pandemia. As crianças foram descritas como fardo social, cujos cuidados na ausência da instituição educativa são insuportáveis. A negação ou invisibilidade da criança enquanto sujeito de direitos foi marca dos memes que circularam reforçando o discurso de ódio que pode ser observado em movimentos denominados Childfree. A diferença entre o momento atual e o discurso chidlfree é que os memes adentraram no discurso familiar, sendo compartilhados por cuidadores, talvez como estratégia de denúncia, desabafo ou busca por redes de solidariedade.

\footnotetext{
Universidade Federal da Bahia, Brasil.

E-mail: julianapsantana@gmail.com

Estudante de Psicologia, na Universidade Federal da Bahia, Brasil.

E-mail: larissa.s.fraga@gmail.com

Estudante de Psicologia, na Universidade Federal da Bahia, Brasil

E-mail: leila.mignac@hotmail.com

4 Estudante de Psicologia, na Universidade Federal da Bahia, Brasil.

E-mail: camila.pinho.mello@gmail.com
}

Soc. Infanc. 4, 2020: 185-288 
A pandemia do Coronavírus tem uma particularidade no que se refere à imagem social das crianças, agora não são grupo de risco mas sim vetores assintomáticos, podendo transmitir a doença. A criança passa de sujeito vulnerável à sujeito perigoso. Pietro (2020) destaca o desaparecimento das crianças espanholas da vida pública em função da pandemia. $\mathrm{O}$ autor levanta questões sobre a imagem das crianças que emergem nesse momento pandêmico, como o fato de que a saída das crianças do espaço público, faz com que elas passem a ser exclusivamente uma questão de cunho familiar. A pandemia trouxe a tona paradoxos que marcam a compreensão da(s) infância(s) e dos modos de vida das crianças. O caráter paradoxal que as circunstâncias de vida das crianças tem sido considerada pela sociedade dos adultos foi abordado por Pinto e Sarmento (1997), e se atualizam neste momento. Crianças são desejáveis enquanto modelo hegemônico de família, mas suas necessidades e características não os são. Assim crianças são desejáveis desde que silenciosas, limpas, obedientes e dispostas a posar nas redes sociais como integrante da família perfeita. Mas são indesejáveis, quando demandam atenção, precisam de cuidados, se rebelam contra as reuniões de trabalho remoto ou não aceitam a disciplinarização dos seus corpos para o acompanhamento das aulas à distância. Somado a isso, une-se uma visão idealizada sobre os cuidados com as crianças que implica um esforço descomunal dos seus cuidadores no sentido de ocupar os seus tempos ou potencializar ao máximo a sua capacidade de aprendizado. Cuidar das crianças nos padrões atuais não implica apenas dar afeto e suprir necessidades básicas, mas sim, ofertar cursos, brincadeiras educativas, exposição a idiomas, etc. Há uma ojeriza a ideia de tempo livre, desinstitucionalizado.

\section{Método}

Realizou-se uma busca dos memes veiculados nas redes sociais no Brasil, especialmente Instagram, Facebook, Twitter e Grupos de Mães do Whatsapp, durante os meses de março e abril de 2020. Nas três primeiras redes, foram utilizadas as hashtags "criança" e "quarentena" como descritores, além de uma navegação por conveniência. Os grupos de whatsapp foram mapeados através da rede de contatos pessoais das pesquisadoras. Trata-se de uma busca não sistemática, mas que possibilita ilustrar muito do material que circulou nas redes sociais neste período. Obviamente, este recorte acaba por ser do grupo de classe média brasileira, sendo essa uma limitação similar àquela evidenciada no trabalho de Àries (Heywood, 2001).

\section{Resultados e Discussão}

A partir das buscas pelas hashtags foi possível encontrar um conjunto de imagens, dividida em dois grupos: o primeiro refere-se às postagens que citam estratégias de cuidados com as crianças. O segundo grupo era formado por imagens que abordavam as crianças de forma genérica e foram selecionadas como exemplos de um discurso socialmente construído.

Para o presente trabalho foram selecionados trinta e oito memes, o Whatsapp se apresentou como a plataforma com o maior número de memes identificados (dezessete), seguido pelo Instagram (oito), TikTok (cinco), Twitter (cinco) e Facebook (quatro). Em relação ao formato, dezessete são imagens, podendo ser acompanhadas ou não por texto, onze vídeos e oito apenas textos.

Apesar dos memes tratarem sobre a relação ou percepção adulta sobre as crianças, não aparece em nenhum deles a perspectiva das mesmas. Essas mais uma vez são silenciadas, sendo sua realidade descrita a partir de uma perspectiva adultocêntrica. As crianças além de simbolicamente silenciadas, são fisicamente contidas em dois dos memes, aparecendo amarradas e com uma fita adesiva em suas bocas. A maioria dos personagens são brancos (40), havendo uma tentativa de desracializar, tornando o personagem azul, por exemplo, como uma tentativa de universalização das experiências. Tal tentativa reforça o apagamento das necessidades de pessoas não brancas, que vivem experiências distintas de infância e parentalidade. A desracialização como estratégia de apagamento das experiências dos negros foi discutida por Bento (2002), afirmando se tratar de uma forma de manutenção da branquitude como padrão. Outro aspecto percebido é a associação da mulher como mãe em todos os memes, sendo que em relação aos homens esse papel é variado (dentre os doze personagens masculinos, apenas cinco desempenham o papel paterno).

Quando se analisa os temas emergentes, evidencia-se as questões estruturais que condicionam a vivência da maternidade e dos cuidados com as crianças. É fundamental considerar que o fio condutor do debate refere-se à estrutura patriarcal e machista da nossa sociedade, estando subentendido a ausência de condições que garantam o cuidado das crianças. As crianças aparecem como problema, afinal denunciam a ausência ou precariedade das condições estruturais, demandam atenção quando é hora do teletrabalho, expõem as mães exaustas, demonstrando a ausência e/ou omissão paterna e de uma rede de cuidado e se rebelam contra estratégias precarizadas de ensino.

Outra temática emergente é a violência simbólica ou física a que as crianças estão submetidas. Há desde o aprisionamento dos corpos, o silenciamento das vozes, até a explicitação da intenção de machucar e/ou exterminar a criança. Obviamente é necessário compreender que a maternidade envolve sentimentos negativos, não havendo uma tentativa de romantização da mesma. Sentimentos de amor e ódio são complementares, estruturantes e não antagônicos (Benhaim e Machado, 2004). Entretanto, o que é explicitado nos memes é a impossibilidade de vivenciar esse ódio sem que isso implique num ato violento contra a criança. 
Uma temática tratada de forma praticamente unânime entre os memes é a ideia da escola ou creche como solução para as famílias quando se pensa no cuidado infantil. Isto remete à compreensão de que o processo de institucionalização das infâncias se deu através da família e da escola. Observa-se um processo de terceirização das crianças e a compreensão muitas vezes da escola como um depositário. Tal processo está atrelado ao sistema capitalista, da precarização do trabalho e redução do papel do estado como provedor do bem-estar social.

Um tema bastante recorrente nos memes é a sobrecarga materna, que incluem diversas dimensões desta questão: a responsabilização das mães pelo acompanhamento e implementação do homeschool, o trabalho doméstico restrito às mulheres, combinado com o trabalho remoto. Os memes também denunciam a invisibilização do trabalho doméstico e materno.

$\mathrm{O}$ último tópico analisado refere-se às imagens sociais emergentes nos memes, que refletem uma imagem de criança e infância subjacente aos discursos socialmente partilhados. Foi possível identificar três dessas imagens: a criança como problema, a criança como sujeito em desenvolvimento e as crianças matáveis. Em 20 dos memes avaliados, é possível perceber que as crianças são apresentadas como sendo a fonte de todos os problemas no momento da pandemia, e sem elas seria muito mais fácil passar por esse período. Inclui-se aqui os memes que trazem referência explícita à saudade da escola, ao desespero por não ter uma escola para onde colocar os filhos, somado ao lamento de ter crianças por perto.

Os memes a seguir ilustram essa categoria:
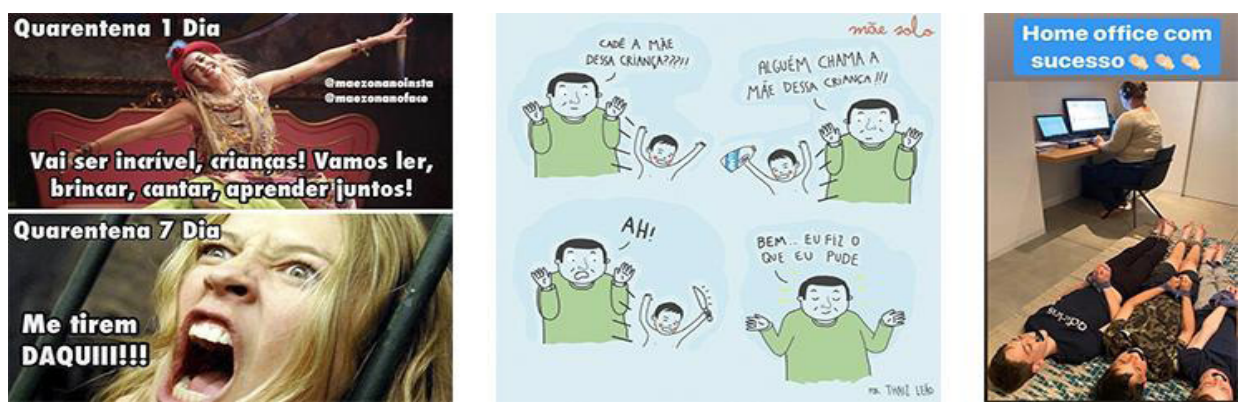

Fonte: Imagens retiradas da internet.

Essa categoria remete à imagem pré-sociológica apresentada por James, Jenks e Prout (1998) da criança má. A imagem da criança má/demoníaca fundamenta-se na idéia de que a criança possui uma natureza maléfica que precisa ser controlada. Contemporaneamente essa categoria parece estar mais relacionada às crianças pertencentes às classes populares (Sarmento, 2007) havendo, no entanto, no momento da pandemia, uma generalização dessa imagem a todas as crianças. A segunda imagem de criança apreendida e que aparece em treze dos memes analisados, é a de criança como sujeito em desenvolvimento. Trata-se do reconhecimento de que as crianças são sujeitos em desenvolvimento que apresentam características e comportamentos decorrentes da sua idade, reconhecendo o trabalho necessário para atender às suas demandas. Nesses memes as crianças não aparecem como fardos, mas como sujeitos que têm necessidades. O cansaço ou a sobrecarga decorrente do atendimento dessas necessidades é denunciado, sendo enfocado principalmente a ausência de condições estruturais que extrapolam à própria criança. Exemplos dessa categoria:
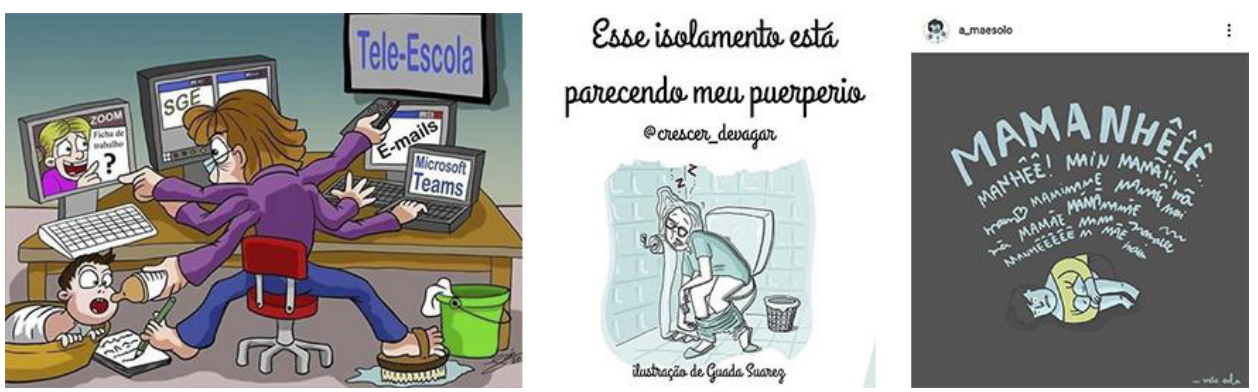

Fonte: Imagens retiradas da internet.

Como última categoria das imagens das crianças, tem-se as crianças matáveis. Trata-se da categoria que mais expressamente reflete um ódio contra as crianças. Esta categoria emerge de memes que apresentam como a única solução para a relação com as crianças o seu extermínio, ou seja, as crianças são alvos de um discurso que prega a sua morte/desaparecimento. Apesar das imagens sociais não possuírem uma relação direta com as ações dirigidas às crianças, há dados que comprovam que a violência doméstica e sexual contra as crianças aumentou no período da quarentena (Campbell, 2020). Exemplos dessa categoria: 

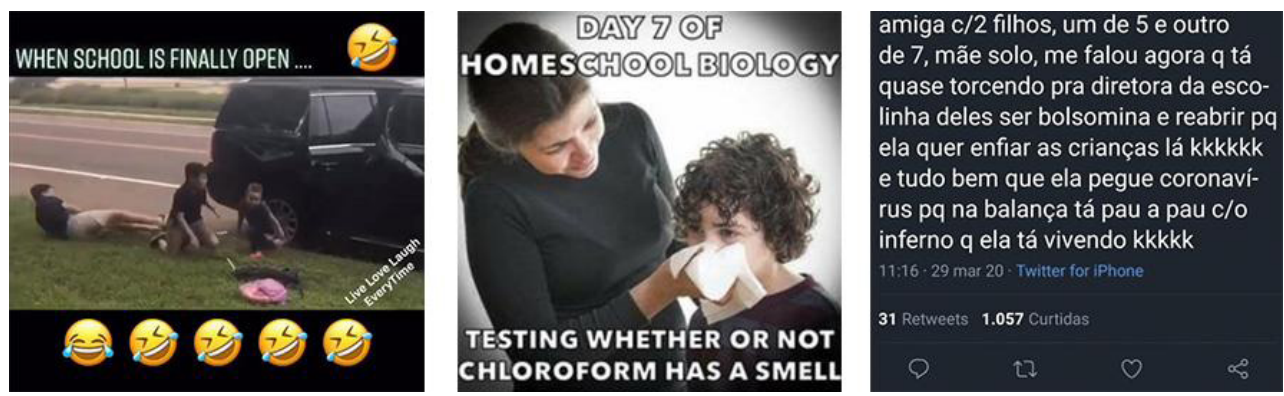

Fonte: Imagens retiradas da internet.

\section{Considerações finais}

Analisar os memes que caracterizam as crianças num momento epidêmico mostrou-se importante estratégia para a compreensão das imagens sociais das crianças e infâncias contemporâneas. Apesar dos avanços sociais, acadêmicos e políticos, as crianças continuam sendo um grupo geracional frequentemente silenciado e alijado dos seus direitos, especialmente no que tange os direitos de participação. A naturalização da violência e estigmatização da criança denuncia, também, a sobrecarga materna, a omissão paterna e a ausência de condições estruturais para garantir a proteção integral das crianças. Somado a isso, sobressai uma lógica produtivista que encara as crianças e suas criancices como desordem, bagunça, excesso. Perde-se com isso uma possibilidade única de ao invés de reclamar das crianças e culpá-las por todas as dificuldades, aprender a ver o mundo com seus olhos.

\section{Referências bibliográficas}

Benhaim, M., Machado, I. (2004). A queixa materna. Estilos Da Clínica, 9(16), 36-49. https://doi.org/10.11606/issn.1981-1624. v9i16p36-49

Bento, M. A. S. (2002). Psicologia social do racismo. Petrópolis: Vozes.

Campbell, A. M. (2020). An increasing risk of family violence during the Covid-19 pandemic: Strengthening community collaborations to save lives. Forensic Science International: Reports, 2, 100089. https://doi.org/10.1016/j.fsir.2020.100089

Corsaro, A. W. (2018). The Sociology of Childhood. Los Angeles: Sage.

Chagas, V. (2020). Da memética aos estudos sobre memes: uma revisão da literatura concernente ao campo nas últimas cinco décadas (1976-2019). In V. Chagas. (Org.), A cultura dos memes: aspectos sociológicos e dimensões políticas de um fenômeno do mundo digital (p. 23-85). Salvador: EDUFBA.

Heywood, C. (2001). A History of Childhood. Cambridge: Wiley.

James, A., Jenks, C., Prout, A. (1998). Theorizing childhood. Cambridge: Polity Press.

Pietro, C. (2020). La asombrosa desaparición de 7 millones de niños españoles por el coronavirus (en línea). https://www.elconfidencial.com/espana/2020-03-22/coronavirus-millones-ninos-espanoles_2509379/, acessado em 26 de Março de 2020.

Pinto, M., Sarmento, M. J. (Coords.) (1997). As Crianças: contextos e identidades. Braga: Centro de Estudos da Criança/Universidade do Minho, 293 páginas. ISBN: 9729732310.

Qvortrup, J. (2009) Childhood as a Structural Form. In J. Qvortrup, W. A. Corsaro, M. H. Honig (eds), The Palgrave Handbook of Childhood Studies (p. 21-33). Palgrave Macmillan, London.

Sarmento, M. J. (2007). Visibilidade Social e Estudo da Infância. In V. M. R. de Vasconcellos, M. J. Sarmento (orgs.) Infância (in) visível (pp. 25-52). São Paulo: Junqueira\&Marin. 